\title{
A clinical study on the effect of programmed labor on feto-maternal outcome
}

\section{Veerendrakumar CM*, Shaila Chikkagowdra}

Department of Obstetrics and Gynecology, VIMS, Ballari 583104, Karnataka, India

Received: 12 August 2016

Accepted: 29 August 2016

\section{*Correspondence:}

Dr. Veerendrakumar C. M.,

E-mail: veerendrakumarcm@gmail.com

Copyright: $\odot$ the author(s), publisher and licensee Medip Academy. This is an open-access article distributed under the terms of the Creative Commons Attribution Non-Commercial License, which permits unrestricted non-commercial use, distribution, and reproduction in any medium, provided the original work is properly cited.

\section{ABSTRACT}

Background: Stress of labor pain disturbs the maternal autonomic functions and liberates catecholamines which predisposes to dysfunctional labor and compromise fetal oxygenation. Freedom from pain improves the environment for both mother and fetus and therapy improves obstetric outcome. The objective of the study was to evaluate the efficacy of programmed labor protocol in providing shorter, safer and relatively pain free deliveries.

Methods: 100 primigravidae with term pregnancy (37-41 wks) meeting inclusion criteria were enrolled in the study. Alternate women were allocated to two groups-study group (50) and control group (50). Programmed labor protocol was initiated in study group and control group were managed expectantly as per hospital protocol. Feto maternal outcome variables were noted.

Results: In study group there was a marked reduction of the active phase of labor. The mean duration of cervical dilatation was nearly double $(2.3+/-0.3 \mathrm{~cm} / \mathrm{hr})$ than the control group $(1.2+/-0.4 \mathrm{~cm} / \mathrm{hr})$ resulting in shortening of the duration of both first as well as second stage in the study group. In the study there was $66 \%$ of women has good pain relief $20 \%$ of women has moderate pain relief. No neonatal mortality or life threatening complications were seen in both the groups.

Conclusions: Programmed labor protocol can be used by all clinicians with high benefit and safety margin.

Keywords: Programmed labor protocol, Pain relief, Safe delivery

\section{INTRODUCTION}

Labor and child birth are natural but painful event. The agony and stress a woman suffers due to labor pain is beyond description. Stress of pain disturbs the maternal autonomic functions and liberates catecholamines which predisposes to dysfunctional labor and compromise fetal oxygenation. Freedom from pain improves the environment for both mother and fetus and therapy improves obstetric outcome. ${ }^{1}$

Epidural analgesia has proved to be beneficial and has contributed significantly to pain relief and improved obstetric outcomes. However in India, wherein the majority of women are cared for in small community hospitals and private maternity homes, facilities for providing epidural analgesia continues to remain a distant dream. Programmed labor protocol is based on incorporation of labor analgesia, active management of labor and monitoring events of labor by a partogram. Therefore the present study was designed to evaluate the efficacy of programmed labor protocol in the local setup and in providing shorter, safer and relatively pain free deliveries.

\section{METHODS}

The present study was conducted in VIMS from 2015 January to 2015 June after ethical committee approval. The study included 100 primigravidae with term 
pregnancy (37-41wks), vertex presentation, in active phase of labor with cervical dilatation of 3-4 cm and fully effaced cervix. Clinical evidence of cephalo pelvic disproportion, hypertension, cardiac diseases, bronchial asthma, diabetes, jaundice, ante partum hemorrhage, abnormal fetal presentation, meconium stained liquor, acute fetal distress cases were excluded from the study.

In all women included in the study, a detailed history, general physical examination and obstetric examination including vaginal examination was done and all the required investigations were carried out. An informed consent for being included in the study was taken and the nature of drugs being used and their possible side effects were explained.

When the patients entered into active phase, artificial rupture of membranes was done if liquor was clear alternate women were allocated to two groups-study group (50) and control group (50). Programmed labor protocol was initiated in study group and control group were managed expectantly as per hospital protocol. As soon as the patients of the study group entered the programmed labor protocol, a partogram was initiated. Maternal vital parameters and fetal heart rate documented periodically. Per vaginal examination carried out after every hour to two hourly intervals. Following regime was adopted. An I.V infusion line with Ringer's lactate $(500 \mathrm{ml})$ started. $6 \mathrm{mg}$ of pentazocin $(30 \mathrm{mg}=1 \mathrm{ml}$ in $9 \mathrm{ml}$ of normal saline then give $2 \mathrm{ml}$ ) and $2 \mathrm{mg}$ of diazepam $(10 \mathrm{mg}=2 \mathrm{ml}$ in $8 \mathrm{ml}$ of normal saline give $2 \mathrm{ml})$ after dilution was administered as a bolus slowly through the infusion line. Inj. Tramadol in the dose of $1 / \mathrm{kg}$ body weight deep intramuscularly was given, along with inj. Drotaverine, 40mg intravenously. Oxytocin was started (5U added to the drip $5 \mathrm{mu} / \mathrm{ml}$ ) gradually increased every $30 \mathrm{~min}$ till 3 contractions lasting for $45 \mathrm{sec}$ in $10 \mathrm{~min}$ if contractions found were inadequate. Inj drotavarine was repeated every $2 \mathrm{hrs}$ if required for maximum of 3 doses. Active management of $3^{\text {rd }}$ stage was done using Inj carboprost 125 microgram intramuscularly.

Level of analgesia assessed using following scale:

0 - No pain relief

1 - Mild pain relief

2 - Moderate pain relief

3 - Excellent pain relief
Active phase duration, II and III stage duration and blood loss during III stage mode of delivery and indication for instrumental and emergency LSCS were noted. Fetal condition of birth (APGAR score), Perinatal morbidity and mortality, Side effect to the mother and child were noted.

The collected data was entered into an excel sheet. After appropriate data cleaning, the data sheet was transferred and analyzed using SPSS software version - 20. Descriptive statistics were used to describe the study variables of the subjects. To compare the categorical qualitative data variables among the two study groups, Chi-square test and Fisher exact test was used and to compare the continuous quantitative data variables ' $t$ ' test was used. The P-values were corrected by the Bonferroni method and a P-value $<0.05$ was regarded as statistically significant.

\section{RESULTS}

Both the groups were comparable in age, gravidity and gestational age. Mean age of women in study group was 23 years while in control group it was 23.2 years. Mean gestational was 38 weeks in subjects and 38.6 in controls.

In study group there was a marked reduction of the active phase of labor. The mean duration of cervical dilatation was nearly double $(2.3 \pm 0.3 \mathrm{~cm} / \mathrm{hr})$ than the control group $(1.2 \pm 0.4 \mathrm{~cm} / \mathrm{hr})$ resulting in shortening of the duration of both first as well as second stage in the study group. This observation was found to be statistically significant $(\mathrm{P}<0.0001)$. It was also observed that there was significant reduction in the duration of third stage, which was due to early separation of the placenta in the study group $4 \pm 1.7 \mathrm{~min}$. Average blood loss was much reduced $75 \pm 25 \mathrm{ml}$ in the study group compared to $160.2+30 \mathrm{ml}$ in the control group which is statistically significant $(\mathrm{P}$ value $<0.0001)$ Two babies born to the women in the study group had APGAR score of $<7$ at 1 and 5 minutes. One of these babies was delivery by caesarean section for fetal distress both the babies had APGAR score 10 after active resuscitation. No apparent cause was found in these two babies. One baby in the control had low APGAR score without apparent cause. None of the neonatal mortality was seen both the group.

Table 1: Comparision of partographic events.

\begin{tabular}{|lllll|}
\hline Parameters & Study group (50) MID \pm SD & Control group (50) MD \pm SD & t- test & P value \\
\hline Rate of cervical dilatation & $2.3 \pm 0.3 \mathrm{~cm} / \mathrm{hr}$ & $1.2 \pm 0.4 \mathrm{~cm} / \mathrm{hr}$ & 15.556 & $<0.001$ \\
\hline Duration of active phase of labour & $3.1 \pm 0.4 \mathrm{hrs}$ & $5.3 \pm 0.5 \mathrm{hrs}$ & -24.29 & $<0.001$ \\
\hline Duration of second stage of labour & $25.3 \pm 6.2 \mathrm{~min}$ & $45.4 \pm 12 \mathrm{~min}$ & -10.522 & $<0.001$ \\
\hline Duration of third stage of labour & $4 \pm 1.7 \mathrm{~min}$ & $6.5 \pm 1 \mathrm{~min}$ & -8.962 & $<0.001$ \\
\hline Average blood loss & $75 \pm 25 \mathrm{ml}$ & $160 \pm 30 \mathrm{ml}$ & -15.391 & $<0.001$ \\
\hline APGAR Score $<7$ at $5 \mathrm{~min}$ & 2 & 1 & $\mathrm{Nil}$ & \\
\hline Perinatal mortality & $\mathrm{Nil}$ & & & \\
\hline
\end{tabular}


For good pain relief the score was given as score 3, moderate pain relief score 2 , mild pain relief score 1 . In the study there was $66 \%$ of women has good pain relief $20 \%$ of women has moderate pain relief. Only $14 \%$ of women had mild pain relief.

$80 \%$ in either group delivered vaginaly around $10 \%$ required instrumental assistance. Incidence of caesarean section in either group was comparable including the indications.

None of the patients had life threatening complications in both the groups; most of them had nausea and vomiting (7\% and 5\%), Giddiness (2\%) and diarrhea (6\%).

Table 2: Pain relief in study group.

\begin{tabular}{|lll|}
\hline Relief score & No $(50)$ & Percentage \\
\hline 1 & 7 & $14 \%$ \\
\hline 2 & 10 & $20 \%$ \\
\hline 3 & 33 & $66 \%$ \\
\hline
\end{tabular}

Table 3: Mode of delivery.

\begin{tabular}{|lll|}
\hline Mode of delivery & $\begin{array}{l}\text { Study group } \\
(50)\end{array}$ & $\begin{array}{l}\text { Control } \\
\text { group (50) }\end{array}$ \\
\hline VD & $40(80 \%)$ & $40(80 \%)$ \\
\hline $\begin{array}{l}\text { Instrumental } \\
\text { (Forceps/ventouse) }\end{array}$ & $5(10 \%)$ & $4(8 \%)$ \\
\hline LSCS & $5(10 \%)$ & $6(12 \%)$ \\
\hline
\end{tabular}

Table 4: Side effects and complications.

\begin{tabular}{|lll|}
\hline Parameters & $\begin{array}{l}\text { Study group } \\
(50)\end{array}$ & $\begin{array}{l}\text { Control group } \\
(50)\end{array}$ \\
\hline Nausea & $7(14 \%)$ & $1(2 \%)$ \\
\hline Vomiting & $5(10 \%)$ & $2(4 \%)$ \\
\hline Giddiness & $1(2 \%)$ & 0 \\
\hline Diarrhea & $3(6 \%)$ & 0 \\
\hline PPH/ trauma & Nil & Nil \\
\hline
\end{tabular}

\section{DISCUSSION}

The protocol of programmed labor is based on incorporation of labor analgesia, active management of labor, and monitoring events of labor by a partogram. ${ }^{2}$

It provided relatively pain free, shorter and safer deliveries.

In the study group, mean rate of cervical dilatation was almost doubled; the duration of all the three stages of labor was markedly reduced; the average blood loss was less. Neonatal morbidity was similar to the control group. There was no fetal or maternal mortality like other studies. ${ }^{1-3}$
The doubling of the rate of cervical dilation and therefore, decrease first in the stage of labor can be attributed to the action of drotaverine which is a superior cervical dilation agent than other anti spasmodic like epidosin or buscopan. ${ }^{4,5}$

There was significant shortening of second stage of labor and pain relief in study group. Pain if long, continued and unrelieved, causes emotional disturbance and ultimately fatigue. ${ }^{6}$ Pain relief prevents maternal hyperventilation, undue muscular efforts and exhaustion there by conserving energy.

Average blood loss of women in the study group was also much less compared to those in control group. This was attributed to the effect of carboprost administered in the active management of third stage which was concordant with other studies. ${ }^{2,3,5}$ The incorporation of partogram was helped to earlier recognition of dystocia and implementation of measures at the same time. ${ }^{7}$ There was no major difference in the percentage of normal delivery in the study as well as control groups. This was in accordance with the observations of other studies. ${ }^{2,3,5}$

Neonatal outcome was comparable between the study group and control group without any significance.

Drugs like Pentazocin used was $1 / 10^{\text {th }}$ the recommended analgesic dose, diazepam is $1 / 5^{\text {th }}$ the recommended single bedtime hypnotic dose and tramadol has been found to be an effective labor analgesic without having deleterious effect on the mother and fetus. ${ }^{8}$

Minor side effect like nausea, vomiting, tachycardia, drowsiness were found and subsided within 12 hours after the delivery and babies were alert and did breast crawl in our study.

\section{CONCLUSION}

In a civilized society freedom from pain is one of the basic rights of a person. Modern obstetrics has no place for prolonged labor with all its ill effects. Most of the labour takes place in peripheral settings. Programmed Labor Protocol can be used by all clinicians with high benefit and safety margin. Thus labor is cherished with pleasure and childbirth becomes a joyous event for the mother.

\section{ACKNOWLEDGMENTS}

Authors would like to thanks to Dr Raghavendra Bellara, Associate Professor, Department of P and SM, VIMS, Ballari 583104 for guidance in statistical analysis.

Funding: No funding sources

Conflict of interest: None declared

Ethical approval: The study was approved by the Institutional Ethics Committee 


\section{REFERENCES}

1. Chauhan R, Gupta R. A clinical study of programmed labour and its outcome. J Obstet Gynaecol \& Family Welfare. 2003;8:9:5.

2. Daftary 1. Programmed Labour. An Indigenously Developed Protocol of Labour Management. Int J Gynecol Obst Ind. 2003;6:47-9.

3. Jyoti M, Singhal P, Choudhary D. Programmed Labor. J Obstet Gynecol India. 2006;56:53-5.

4. Yuel VI, Kaur V, Kaur DP. Programmed Labour for optimizing labour and delivery. JK Science. 2008;10(2);62-4.
5. Mishra SL, Toshniwal A, Banerjee R. Effect of drotaverine on cervical dilatation. A comparative study with epidosin (Valethamate bromide). J Obstet Gynecol India. 2002;52(3):76-9.

6. Daftary SN, Chakravarti S. Normal Labour.in Holland and Brews Manual of Obstetrics, $15^{\text {th }}$ edition; 1991:304-27.

7. Singh KC, Jain P, Goel N, Saxena A. Drotavenine hydrochloride for augmentation of labour Int $\mathrm{J}$ Gynaecol Obstet. 2004;84(1):17-22.

8. Satoskar R, Bhandarkar S, Rege N. Pharmacology and Pharmacotherapeutics. Popular Prakashan. 21st edition: $109,151,155$.

Cite this article as: Veerendrakumar CM, Chikkagowdra S. A clinical study on the effect of programmed labor on Feto-Maternal outcome. Int J Reprod Contracept Obstet Gynecol 2016;5:3357-60 